\title{
The Development of the Irish Fish Farming Industry
}

\author{
Proinnsias Breathnach
}

Department of Geography, St. Patrick's College, Maynooth

\section{Origins and Growth of the Fish Farming Industry}

Fish farming (i.e. the cultivation of fish in controlled conditions) has developed rapidly over the last 20 years in response to growing shortages of wild fish relative to prevailing markets. The industry has been dominated by the salmon sector which in turn has been dominated by Norway, which accounts for about two thirds of international production. However, the strong nature of the market for farmed salmon (at least until recently) has drawn many other countries, including Ireland, into the industry.

Modern fish farming in Ireland originated in the $1950 \mathrm{~s}$, and was originally focused on freshwater trout. However, in the 1970s the focus of the industry shifted to salmon production. Ireland has an excellent physical environment for marine fish farming, with a heavilyindented coastline providing sheltered sites, availability of relatively disease-free natural wild stock, and unpolluted water. Salmon farming was initiated in 1972 by the Electricity Supply Board, which had developed expertise in salmon rearing for the purpose of restocking and managing rivers on which hydropower stations had been built. The following year Gaeltarra Éireann, the state agency responsible for the development of the Gaeltacht areas, began a mussel farming operation, expanding subsequently into oyster and salmon cultivation.

Further important steps in the promotion of the fish farming industry included the introduction of a licensing system under the 1980 Fisheries Act and the development of financial incentives by Údarás na Gaeltachta (which replaced Gaeltarra Éireann in 1980), Bord Iascaigh Mhara (the Irish Sea Fisheries Board) and FEOGA (the EC Agriculture Fund).

The Irish fish farming industry experienced slow growth in the initial, experimental stages, but expanded rapidly from the early 1980s on (Table 1 and Figure 1). Until 1989, the industry was confined to four species: salmon, trout (both sea and freshwater), mussels and oysters. Most of the early growth was accounted for by the salmon sector, which more or less doubled the value of its output in successive years in 1987 and 1988. By contrast, the rate of growth in the other three sectors has been limited and uneven. In 1989 , clams made a modest entry into the fish farming scene, to be followed by abalone in 1990. Farmed fish have now come to account for a significant proportion of overall Irish fish production, representing $22 \%$ of the value of the total catch in 1988, compared with just $5 \%$ in 1980 .

\section{Fish Farm Species}

\section{Salmon}

The salmon sector accounted for three quarters of the total output of the Irish fish farming industry in 1990. In international terms, Ireland became the third main producer of farmed Atlantic salmon by 1985 albeit a long way behind the "big two", Norway and Scotland. Salmon farming requires substantial levels of investment, not only in rafts, cages, and smolt production, but also in feeding systems and measures to combat disease, predators and parasites, to which the salmon are particularly vulnerable, given that they are reared in confined spaces. As a result, most salmon farms have been initiated by substantial corporate investors, and the industry is dominated by a small number of large operators.

In 1991, some 22 salmon farms were in operation, as well as 10 onshore hatcheries (O'Connor and Whelan, 1991). The farms provided the equivalent of 490 fulltime jobs, or an average of 22.3 per enterprise. Most employment in the sector is full-time, by contrast with the shellfish sector (below). The bulk of the farms are 


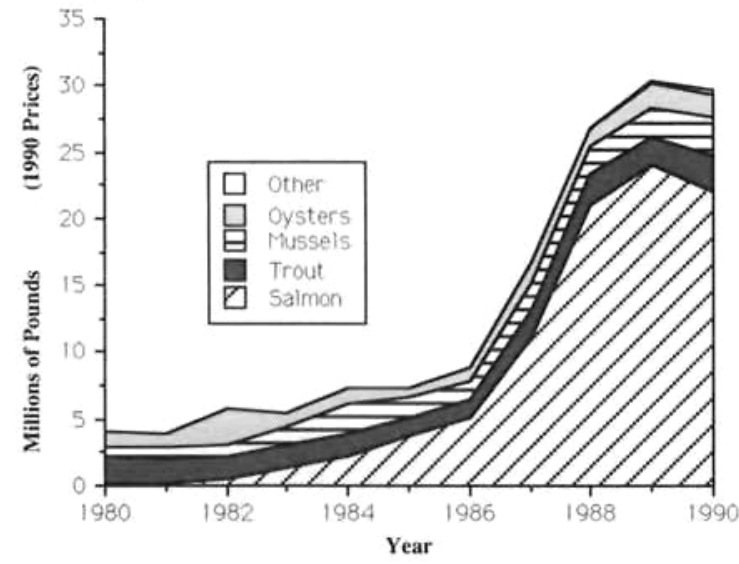

Figure 1: Value and Composition of Fish Farming Production 1980-90

to be found along the northwest and west coasts, especially North and Southwest Donegal and Galway (Killary, Clifden and South Connemara) (Figure 2). Salmon hatcheries are mainly to be found in onshore sites adjacent to the main marine farm sites, apart from a cluster in the vicinity of County Wicklow, in the southeast. These latter are mainly offshoots from trout farms which are also concentrated in this area.

Both the volume and value of farmed salmon production grew rapidly in the second half of the 1980 s, but a market glut led to sharply reduced prices in 1990. This created severe difficulties for some operators, although the majority continued to remain viable, with some being quite profitable (O'Connor and Whelan, 1991). Pressure on Norway to restrict sales has allowed the market to recover more recently.

\section{Trout}

Despite leading the way in the Irish fish farming industry, the trout sector rapidly fell behind the salmon sector in the second half of the 1980s and now accounts for less than $10 \%$ of the industry's total output. This relative decline is largely due to the superior prices available for salmon. While the sea trout sub-sector expanded significantly later in the decade, it has consistently been overshadowed by the freshwater sub-sector.

Eleven trout farms were in operation in 1991. Sea trout farms are to be found interspersed with salmon farms along the west and southwest coasts while freshwater trout farms are mainly found in the east and southeast (Figure 2). As with salmon farms, employment in the trout sector is mainly of a full-time nature. Total full-time equivalent employment amounted to 52 in 1991, or 4.7 per farm.

\section{Mussels}

Mussel farming in Ireland is of two kinds. Intensive farming involves cultivating mussels attached to ropes (or, more recently, poles) suspended from rafts or, increasingly, from longlines buoyed up by floats. Intensive farming is by far the most common type of mussel farming in Ireland. Extensive farming involves dredging seed mussels from natural beds and re-laying them in prepared sea-bottom beds in sheltered locations. This type of mussel farming has only been developed

Table 1: Value and composition of fish farming production $1980-90$ ( $£ 000,1990$ Prices)

\begin{tabular}{|rrrrrrr|}
\hline & Salmon & Trout & Mussels & Oysters & Other & Total \\
\hline 1980 & 153 & 1,987 & 762 & 1,121 & - & 4,023 \\
1981 & 213 & 1,876 & 858 & 965 & - & 3,912 \\
1982 & 521 & 1,734 & 877 & 2,616 & - & 5,748 \\
1983 & 1,404 & 1,711 & 1,242 & 1,165 & - & 5,522 \\
1984 & 2,232 & 1,626 & 2,304 & 1,188 & - & 7,350 \\
1985 & 3,705 & 1,431 & 1,459 & 723 & - & 7,318 \\
1986 & 5,144 & 1,326 & 1,350 & 1,062 & - & 8,882 \\
1987 & 11,117 & 2,022 & 2,046 & 1,593 & - & 16,778 \\
1988 & 20,965 & 2,345 & 2,073 & 1,405 & - & 26,788 \\
1989 & 24,060 & 2,065 & 2,270 & 1,755 & 205 & 30,355 \\
1990 & 22,100 & 2,700 & 2,900 & 1,600 & 400 & 29,700 \\
\hline
\end{tabular}

Sources: Aquaculture Ireland (various issues); Bord Iascaigh Mhara: Annual Reports. 


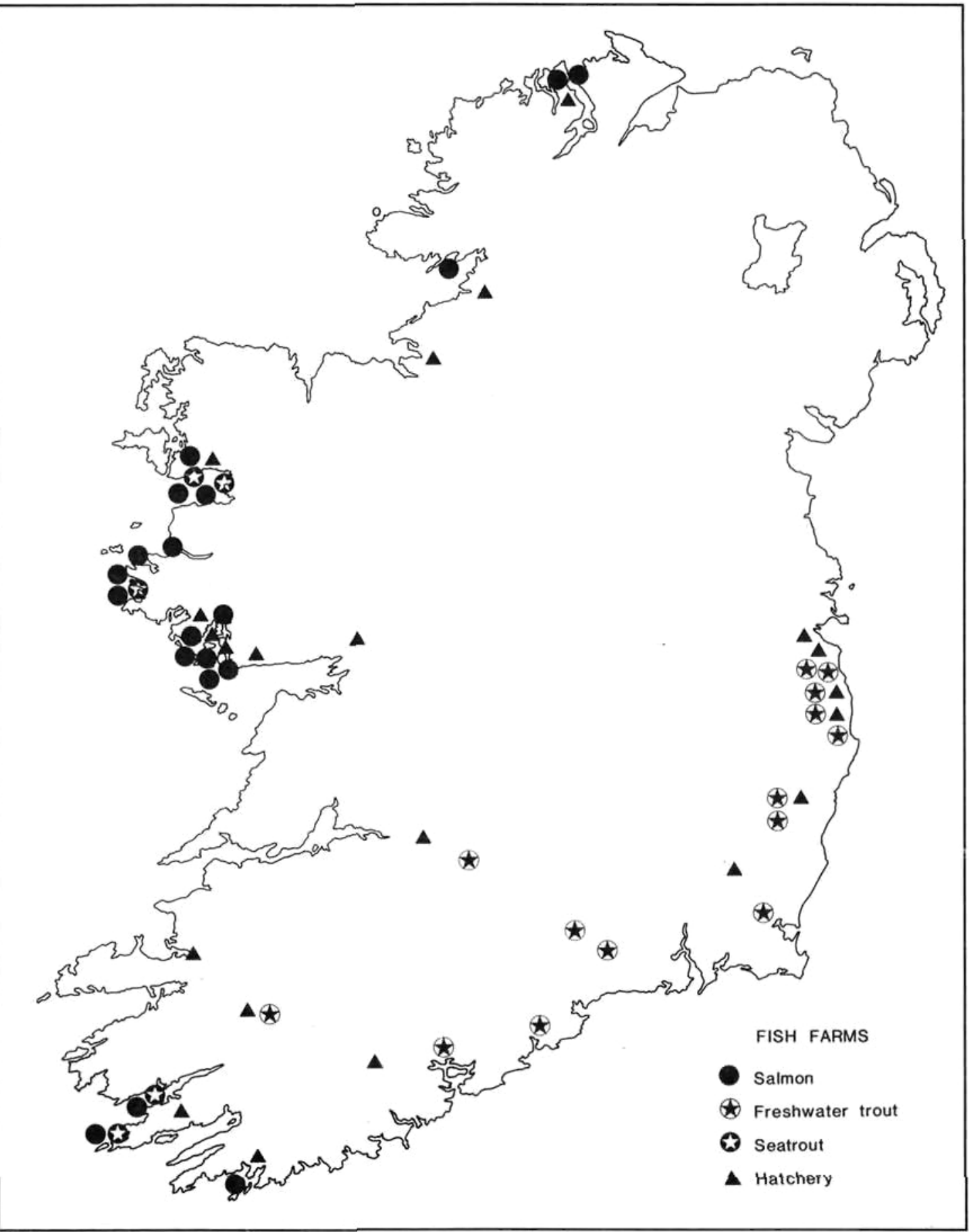

Figure 2: Locations of Finfish Farms 1990 
at a couple of locations. Rope mussel cultivation has grown consistently through the 1980 s, with the exception of 1986, when the sector was badly affected by the phytoplankton bloom known as "red tide". Bottom mussel cultivation has been much more uneven in its development, although the trend through the decade was nevertheless strongly upward. The main concentration of mussel farms is in the southwest, especially Bantry and Kenmare Bays (Figure 3).

Mussel production relies to a much greater extent on part-time workers than salmon or trout farming. In full-time equivalents, the 54 rope mussel farms employed an average of only two people each in 1991, whereas the corresponding figure for the four largerscale bottom mussel operations was 17.5 (O'Connor and Whelan, 1991).

\section{Oysters}

Two species of oyster are currently cultivated in Ireland - the native or flat oyster and the Pacific or rock oyster. The native oyster is cultivated both extensively (on the seabed) and intensively (on racks of trays suspended in the sea). The successful development of intensive methods of cultivating native oysters has proved to be technically difficult, whereas intensive farming of Pacific oysters is much less problematical. While the trend in the volume of output of intensively cultivated native oysters has been continuously upward, output of extensively cultivated oysters has been extremely variable. The main concentration of oyster farms include Carlingford Lough, Galway and Clew Bays, and in the southwest (Figure 3).

Pacific oysters have generated a large number (62) of small-scale operations, each providing, on average, the equivalent of 1.8 full-time jobs (O'Connor and Whelan, 1991). By contrast, there were only seven native oyster units in operation in 1991, generating an average of 9.6 full-time job equivalents each. For both species of oyster, the tendency is for most employment to be part-time.

\section{The Developmental Impact of Fish Farming}

Given a total output of less than $£ 30 \mathrm{M}$ in 1990 and total direct employment in full-time equivalents of less than 1,000 , the Irish fish farming industry is of modest proportions when set in the context of the overall national economy. However, the significance of the industry assumes much greater proportions in a regional context, especially given the fact that it is mostly concentrated in the remotest parts of Ireland, along the western coastline.

The growth of the fish farming industry in these areas is seen to convey numerous advantages. It is not only based on local natural resources, but also links in with the established fishing tradition of the region. It has not only created additional employment but, as has been described earlier, much of this is of a part-time nature, and therefore fits in well with a long-established tradition of occupational pluralism in western rural regions where many people are part-time farmers, fishers and turf-cutters, frequently augmented by providing tourist accommodation and engaging in occasional paid employment.

The large capital investment required of finfish farms has meant that ownership has tended to reside in externally-based companies. As against this, these farms provide much full-time employment, most of which is sourced locally. In addition to the direct employment provided in fish farming, there is increasing evidence of spin-off employment creation in the form of backward and forward linkages, both within the western region itself and elsewhere in the country. The former include cage and raft fabrication, net making, fish feed production, boat making and repair, marine engineering, and scientific and veterinary services. Forward linkages include processing, marketing and distribution.

O'Connor and Whelan (1988) estimate that, for every full-time equivalent job created directly in fish farming, another 1.11 jobs are created in linked industries and from the general multiplier effects of the spending of fish farms and their employees. On this basis, it can be reckoned that up to 1,000 additional jobs had been created in Ireland by 1991 as a result of the spin-off effects arising from the emergence of the fish farming industry. A large proportion of these will have been created within the western coastal region itself: O'Connor and Whelan (1988) estimated that one half of the spin-off employment arising from the fish farming industry in the Gaeltacht is located in the Gaeltacht itself.

There has been considerable public controversy and debate concerning the environmental effects - potential, actual, and alleged - of fish farming. These include the accumulation of fish effluents and uneaten feed debris underneath fish cages; the administration to farm fish 


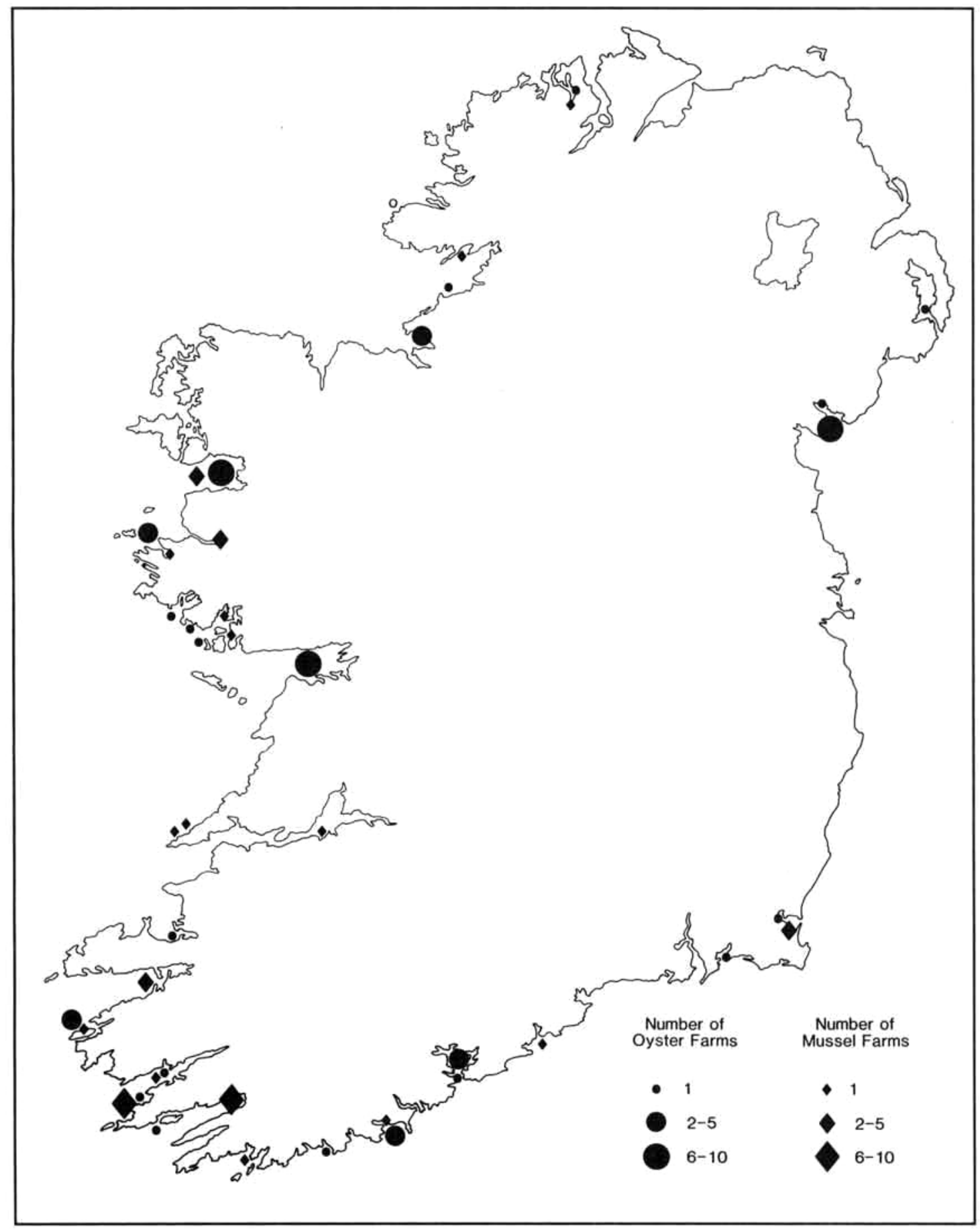

Figure 3: Locations of Shellfish Farms 1990 
of chemicals which may have toxic effects on other marine life and on fish farm workers, as well as causing stress to the farm fish themselves; admixing of escaped farm fish and wild fish, which may disrupt migratory and other instincts in wild fish; illegal dumping of dead fish (which have been periodically generated in large numbers due to attacks of disease); the spread of hatcheries in freshwater rivers and lakes in response to the growing demands for smolts by salmon farms, with associated fears of interference with angling interests and of pollution of drinking water supplies; the impact of fish farming installations on the visual amenity of coastal regions, and the interference they may cause for other users of the marine environment.

The concerns of environmental interests were addresed to some extent by the introduction, in 1990 , of new EC regulations requiring an Environmental Impact Statement for all seawater salmonid farms with annual output exceeding 100 tonnes; all freshwater operations on lakes and upstream of drinking water intakes: and freshwater hatcheries exceeding one million smolts. Nevertheless, there would appear to be considerable merit in the argument being made by environmentalists that what is needed is a comprehensive Coastal Zone Management Programme, designed to reconcile the various interest groups affected by developments in coastal areas, and devised and monitored by an authority comprising representatives of these groups. Such a programme was initiated by Norway in 1987.

\section{Future Prospects}

Technically and economically, there remains considerable scope for further expansion of Ireland's fish farming industry. O'Connor and Whelan (1988) suggest that limitations relating to site suitability will restrict Ireland's ultimate salmon production to 15,000 tonnes, or just over twice the level achieved in 1990. The Irish Shellfish Association projects that Ireland is capable of producing up to $\mathrm{f} 56.6 \mathrm{M}$ worth of farmed shellfish, or ten times the level actually produced in
1990. Such a level of output would provide a full-time employment equivalent of 3,750 , or nine times current levels.

The main area of future expansion would appear to lie in the shellfish sector. especially given the current economic difficulties and environmental concerns surrounding the salmon sector. The shellfish sector poses few environmental problems and, for the most part, faces strong market prospects. It is also clearly desirable to diversify the Irish fish farming industry, which is currently over-dominated by the salmon sector. Progress is also being made towards broadening the range of species involved in fish farming. In 1989. the first commercial output of clams came on the market, with abalone following in 1990. Research is also being conducted into the possibilities of artifically cultivating escallops, sea urchins, whelks, periwinkles, lobsters, halibut and turbot.

Successful development of the industry to its full potential, however, will require a wide range of additional measures. Better and more efficient legislative and administrative procedures governing the industry are urgently required. There is a pressing need for better organisation of small-scale producers, including co-operative structures to deal with training. transportation, processing, marketing and the hiring in of technical expertise. New forms of financial assistance are required, especially for small producers. Current aid packages are mainly geared towards capital equipment, whereas working capital is frequently a problem for new entrants to the industry. An increased research input by both the state and the producers themselves is also necessary. At the moment, even the most basic oceanographic and hydrographic data are in short supply.

Fish farming has already made an important contribution to the economic and social development of Ireland's most marginal regions. However, this contribution could take on a different order of magnitude if a properly co-ordinated long-term approach is adopted to the realisation of the industry's potential.

\section{References}

O'CONNOR, R. and WHELAN B.J. (1988) Aquaculture in the Gaeltacht: its economic and social impact. Údarás na Gaeltachta. Na Forbacha.
O'CONNOR R. and WHELAN B.J. (1991) An Economic Assessment of Aquaculture in Ireland. The Economic and Social Research Institute, Dublin (mimeo). 